\title{
Intention to use hearing aids: a survey based on the theory of planned behavior
}

\author{
This article was published in the following Dove Press journal: \\ Patient Preference and Adherence \\ 17 September 2014 \\ Number of times this article has been viewed
}

\author{
Hartmut Meister' \\ Linda Grugel' \\ Markus Meis ${ }^{2}$ \\ 'Jean Uhrmacher Institute for Clinical \\ ENT Research, University of Cologne, \\ Cologne, Germany; ${ }^{2}$ Hoerzentrum \\ Oldenburg, Oldenburg, Germany
}

Correspondence: Hartmut Meister Jean Uhrmacher Institute for Clinical ENT Research, University of Cologne, Geibelstr 29-3I, D-5093I Cologne,

Germany

Tel +4922I 47897003

Fax +49 22I 47897010

Email hartmut.meister@uni-koeln.de
Objective: To determine the intention to use hearing aids (HAs) by applying the theory of planned behavior (TPB).

Design: The TPB is a widely used decision-making model based on three constructs hypothesized to influence the intention to perform a specific behavior; namely, "attitude toward the behavior", "subjective norm", and "behavioral control". The survey was based on a TPB-specific questionnaire addressing factors relevant to HA provision.

Study sample: Data from 204 individuals reporting hearing problems were analyzed. Different subgroups were established according to the stage of their hearing help-seeking.

Results: The TPB models' outcome depended on the subgroup. The intention of those participants who had recognized their hearing problems but had not yet consulted an ear, nose, and throat specialist was largely dominated by the "subjective norm" construct, whereas those who had already consulted an ear, nose, and throat specialist or had already tried out HAs were significantly influenced by all constructs. The intention of participants who already owned HAs was clearly less affected by the "subjective norm" construct but was largely dominated by their "attitude toward HAs".

Conclusion: The intention to use HAs can be modeled on the basis of the constructs "attitude toward the behavior", "subjective norm", and "behavioral control". Individual contribution of the constructs to the model depends on the patient's stage of hearing help-seeking. The results speak well for counseling strategies that explicitly consider the individual trajectory of hearing help-seeking.

Keywords: hearing aid uptake, motivation, attitude, subjective norm, behavioral control

\section{Introduction}

Hearing loss is a common health condition, especially in older adults. Recently, a large epidemiological study showed prevalence figures ranging from about $9 \%$ in people aged 45-49 years, up to 50\% in people aged 70-74 years. ${ }^{1}$ Most people with sensorineural hearing loss could potentially benefit from hearing aids (HAs). However, despite the significant progress in HA technology over the last 2 decades, the proportion of hearing-impaired people using HAs still remains small. Especially within the elderly population, who are frequently affected by presbycusis, HAs are not widely used. The prevalence of HA ownership among people with hearing impairment has been reported by several studies to be between $6 \%$ and $41 \%{ }^{2-6}$ Furthermore, a substantial percentage of HA owners do not use their devices on a regular basis. ${ }^{7-9}$

A review of the literature shows that various studies have dealt with the question of what influences hearing-impaired people to seek help and, furthermore, what influences them to use HAs (ie, acoustic amplification) on a regular basis. Recently, Knudsen et $\mathrm{al}^{10}$ provided an overview of the research conducted between 1980 and 
2009 with regard to factors influencing HA use. Although most studies have focused on use and satisfaction as outcome variables instead of help-seeking and HA uptake, several factors that may influence the willingness to use HAs have been identified, such as personality traits, stigmatization, and self-perceived hearing impairment.

These findings are in line with those of the Meyer and Hickson ${ }^{11}$ review. These researchers found that help-seeking and/or HA uptake were more likely if the people were older, reported larger self-perceived hearing problems, and believed there were more benefits to HAs than barriers to amplification. Meyer and Hickson also stated that there were additional important factors, such as the personality of the individuals concerned.

This factor was addressed by Cox et $\mathrm{a}^{12}$ who showed that with respect to their personality profiles, HA seekers are not simply a random sample of the general population or of the hearing-impaired population. HA seekers tended to be pragmatic, conforming, and conventional; they were higher in internal locus of control and lower in social support coping mechanisms compared with the general population. Cox et al suggested that differences in personality traits might be a useful guide for selecting treatment approaches and developing expectations for patients.

The role of expectations in the motivation for HA uptake was considered in a study by Meister et al. ${ }^{13}$ The authors investigated the factors underlying the willingness to use HAs in a sample of 100 hearing-impaired participants. They identified three significant factors (expectations toward improvement of quality of life, stigmatization, and self-rated hearing ability) that accounted for about $55 \%$ of the variability in the willingness scores.

Laplante-Lévesque et $\mathrm{al}^{14}$ expanded on this research by examining predictors of rehabilitation intervention decisions with respect to different options (HA use or communication programs). They identified seven intervention decision predictors, revealing that their hearing-impaired participants more frequently opted for HA provision if subsidized hearing services were available, hearing impairment was more severe, and the hearing disability was perceived by others and the person concerned.

These findings add another dimension that possibly influences HA use; namely, the role of significant others. Several studies showed that health care professionals, family members, and friends and colleagues have an influence on the willingness to use HAs. ${ }^{11,15,16}$ Significant others might act as motivators and supporters of HA use but can also become an obstacle, especially when stigmatization becomes an issue. ${ }^{17}$
Because the incidence of hearing impairment is presumed to be increasing as a result of demographic change and because hearing diseases are one of the most frequent age-related chronic conditions, the determinants of help-seeking behavior are of great interest. Revealing these is not a simple task for several reasons. First, the people are typically "inaccessible" until they seek help. Second, the key factors are not necessarily static but, rather, change dynamically with the process of aural rehabilitation: Meis and Gabriel ${ }^{4}$ interviewed 190 hearingimpaired people who were not yet fitted with HAs, over the course of a 9-month period, regarding different technical and nontechnical aspects of HA provision. During this period, only $12 \%$ of the participants decided to purchase HAs. The reasons for declining HAs differed with respect to the point in time at which this decision was taken (eg, before or after the visit to an ear, nose, and throat [ENT] specialist or during fitting). The authors speculated that participants' insufficient information about HAs was a crucial factor in help-seeking behavior.

Taken together, a number of variables such as auditory and psychosocial factors have been identified as potentially influencing HA use. However, the studies are inconclusive, as they typically applied various research designs and focused on different aspects of HA provision, and thus give a somewhat scattered picture. An alternative approach to explaining why some people more likely use HAs than others is to apply established models of help-seeking and decision making in hearing health care. Only recently, models such as the "health belief model"18 or the "Transtheoretical Stages-of-Change Model" ${ }^{\prime 19}$ have been applied with regard to HA provision. ${ }^{20}$

One frequently used decision-making model in health care research is based on the theory of planned behavior (TPB). ${ }^{21}$ The TPB is a psychological model designed to predict and explain types of human behavior in specific situations. Provided the specific behavior is under volitional control, it is assumed that the intention to perform the behavior is strongly related to the actual activity. Furthermore, it is hypothesized that the intention itself can be predicted by three different key constructs: the "attitude toward the behavior" (ie, positive or negative evaluation of the behavior), "subjective norms" (ie, social normative pressures), and "behavioral control" (ie, perceived barriers to perform the behavior; see methods for more detailed information). ${ }^{21}$ The TPB has rarely been used with respect to hearing health care. In fact, we are only aware of the study by Wiesner and Tesch-Römer, ${ }^{22}$ who used the TPB to determine the behavior of elderly HA users. However, we find it highly suitable with regard to factors important for HA uptake, as it considers both "internal" factors such as attitude and behavioral control and important "external" 
factors (subjective norm) with regard to encouragement or opposition of significant others. ${ }^{23}$ In the present study, we applied the TPB to determine the intention to use HAs in individuals reporting hearing problems, while considering different stages of hearing help-seeking. Therefore, we developed a specific TPB questionnaire and computed TPB models for different subgroups, including persons who had noticed hearing problems but had not yet consulted an ENT specialist, through to persons who already use HAs. We hypothesized that the intention to use HAs can be predicted by the TPB models and that the individual contribution of the TPB key constructs to the models depends on the different stages of hearing help-seeking. Specifically, we anticipated that the influence of "subjective norm" on the intention to use HAs would be largest at early stages of HA provision and that the influence of "attitude" and "behavioral control" would increase as the participants proceeded on the trajectory of aural rehabilitation and gained more information about the possible benefits of amplification.

\section{Methods}

\section{Theoretical model}

The TPB was developed on the basis of Fishbein's Theory of Reasoned Action. ${ }^{24}$ The rationale behind the model is that a person's behavior is determined by the intention to perform the behavior. According to Ajzen, ${ }^{21}$ the intention is in turn determined by three distinct constructs: "attitude toward the behavior", "subjective norm", and "behavioral control". These can be explained as follows: the attitude toward the behavior refers to "whether the person is in favor of doing it", the subjective norm corresponds to "how much the person feels social pressure to do it", and the behavioral control relates to "whether the person feels in control of the action in question". ${ }^{21}$ On the one hand, these constructs can be measured in a direct manner; for instance, by asking respondents about their overall attitude. On the other hand, it is assumed that each construct results from underlying beliefs held by the person, which might be taken as indirect measures. However, as stated by Francis et $\mathrm{al}^{25}$ if the goal of the research is to conduct an analysis to predict variance in behavioral intentions, it is sufficient to measure intentions and the three predictor variables, using direct measures. As this was the goal of the present study, only outcomes from direct measures are reported here.

The TPB model structure is shown in Figure 1, where the linear regression coefficients $b_{1 \ldots 3}$ indicate the strength of the relationships between the three constructs and intention and the correlation coefficients $r_{12 \ldots .23}$ show the partial correlations between the constructs. The core model represented by the data of the present study is printed in black.

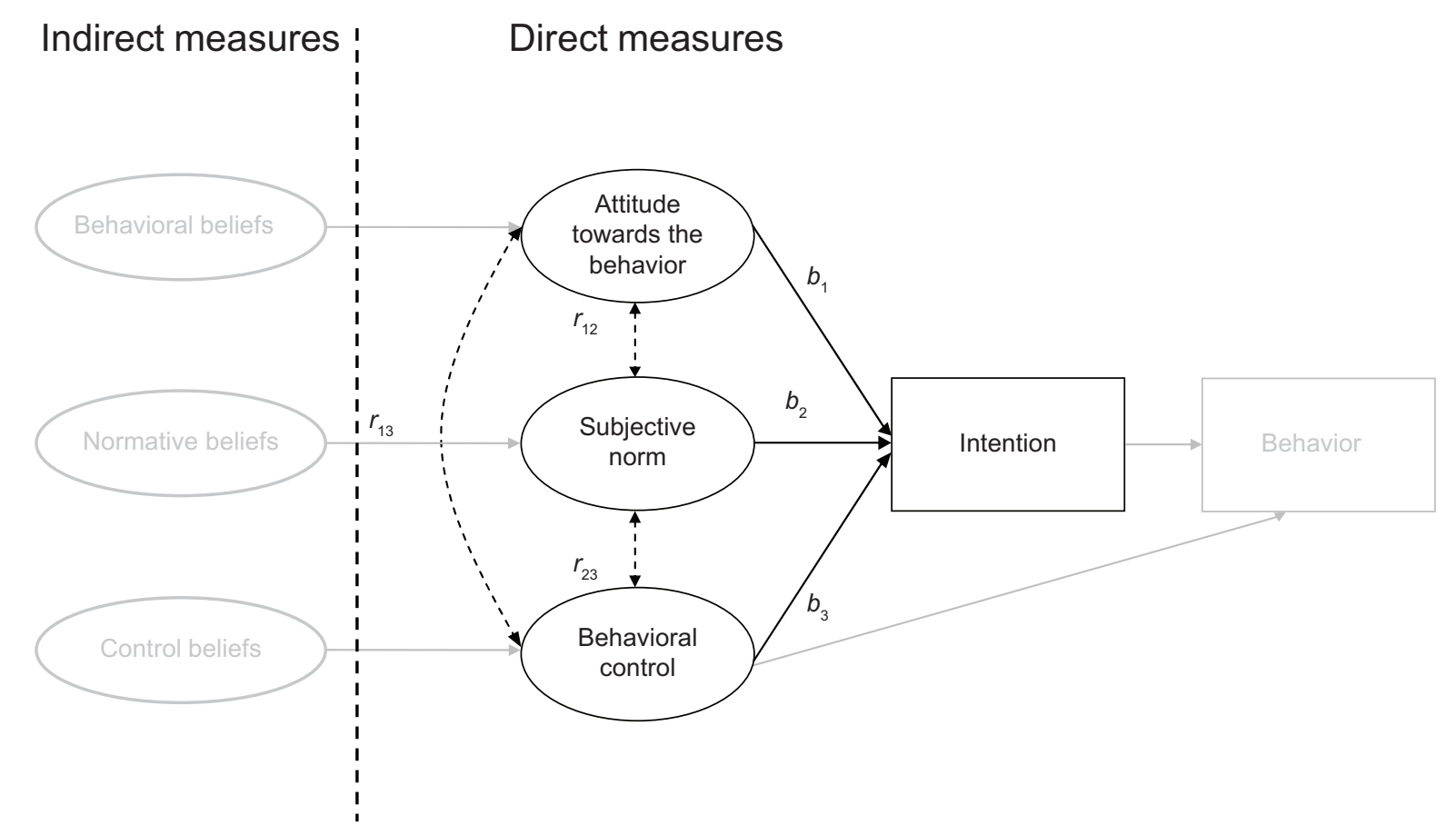

Figure I Schematic of the theory of planned behavior model.

Notes: Adapted from Ajzen ${ }^{21}$ and Armitage and Conner. ${ }^{36}$ The linear regression coefficients $b_{1} \cdots_{3}$ indicate the strength of the relationships between the three constructs and intention. The correlation coefficients $r_{12} \cdots 23$ show the partial correlations between the constructs. 


\section{Materials}

A questionnaire to measure the constructs of the TPB was developed following the guidelines of Francis et $\mathrm{al}^{25}$ who described a detailed nine-step procedure for the design of the questionnaire. In addition, the originator of the TPB, Icek Ajzen, was involved in the development and approved the draft of the instrument. "Attitude" was measured with four items, "subjective norm" and "perceived behavioral control" were measured with three items each, and intention was measured with four items. Response format was a Likert scale coded 1 to 5 . Points credited to responses to negative statements were reversed with data processing. A translation of the questionnaire is given in the Figure S1.

In addition to the TPB items, a number of secondary questions were asked of the participants. Hearing problems were captured with the question, "Do you feel you have a hearing loss?" This single question has proven to be an effective and sensitive instrument for the screening of presbycusis. ${ }^{26}$ Two additional questions addressed the severity of hearing problems in quiet and in adverse listening situations (see Figure S1). Moreover, demographic data such as sex, age, marital status, number of people in the household, level of education, and employment situation were assessed.

\section{Participants}

Participants were recruited from two different sites in Cologne and Oldenburg, Germany, respectively (including their environs). As the aim was to access the whole range of people with hearing problems, including those who had not yet sought help, it was decided to recruit participants via announcements in local newspapers, rather than from the files of the two audiology centers. People who felt they had hearing problems but who did not yet own HAs were invited to contact the audiology centers involved in the study if they were willing to participate in the survey. The participants then received the questionnaire together with a post-paid and self-addressed envelope. They were offered compensation of $€ 6$ for filling in the questionnaire. Because of organizational issues, compensation could only be paid to those who conveyed bank account details. Each of the participants provided their written informed consent. The study protocol was approved by the Ethics Committees of the University of Cologne and Oldenburg.

Of the 325 people who contacted the centers, 301 returned the questionnaire. Respondents who did not answer the two questions with respect to hearing problems in quiet and in adverse listening conditions were excluded from the analyses, as it was not clear whether they could actually estimate their hearing problems, leaving 285 participants. Of those, 204 participants completely filled in the TPB parts of the questionnaire. The age of these participants ranged from 35 to 87 years (mean, 65.2 years; standard deviation, 9.9 years). Sixty-nine participants were women and 132 were men (sex was not reported by three participants). As the aim of the study was to identify the determinants of the intention to use HAs in relation to the stage of hearing help-seeking, the participants were divided into different subgroups. Stage 1 was composed of people who indicated they had noticed their hearing problems but had not yet consulted an ENT specialist. Stage 2 was composed of people who indicated they had already consulted an ENT specialist but had not yet tried out HAs. Stage 3 was composed of people who were in the process of trying out HAs but who did not yet own HAs. The definition of the stages was motivated by the typical HA provision process in Germany: After a person has already perceived hearing problems and has decided to seek help, this process at first includes a visit to the general practitioner followed by referral to an ENT specialist, who diagnoses hearing impairment and prescribes the HAs, and finally, a subsequent visit to an acoustician for the purpose of fitting and trying out different HAs. In Germany, HAs are partly financed through the public health system (at present up to approximately $€ 700$ per device).

Although not expected at the outset of the study, a smaller group of participants $(\mathrm{n}=28)$ indicated they were indeed HA owners. This might be because some weeks had elapsed between the announcement of the study and the delivery of the questionnaires. It was decided to include these data in the analysis, as it seemed interesting to compare the outcomes for patients with HAs with those of participants who had tried out HAs (stage 3), and with those of the Wiesner and Tesch-Römer ${ }^{22}$ study. The corresponding subgroup was labeled stage 4 . Demographic characteristics were similar across stages (Table 1). There were no statistically significant group differences with respect to age ( $t$-tests all $P>0.05)$. For all subgroups, most of the participants were male, married and shared a household with their spouses. The total number of people living in the household did not significantly differ between the groups ( $t$-tests, all $P>0.05$ ). Because educational systems are not directly comparable from country to country, we decided to define levels with an increasing degree of education. Here, educational level 0 stands for having not graduated from school. Educational levels 1-4 include different specifications of secondary schools, with level 1 signifying vocational training and level 4 general access to university studies. With respect to the four subgroups, there were no significant 
Table I Demographic characteristics of the participants

\begin{tabular}{|c|c|c|c|c|}
\hline & \multicolumn{4}{|c|}{ Stage of hearing help-seeking } \\
\hline & $\mathbf{I}$ & 2 & 3 & 4 \\
\hline \multicolumn{5}{|l|}{ Sex } \\
\hline Male & $25(62.5 \%)$ & $43(62 \%)$ & $45(67.2 \%)$ & $19(67.8 \%)$ \\
\hline Female & 15 (37.5\%) & $25(36.5 \%)$ & $20(29.8 \%)$ & 9 (3I. $2 \%)$ \\
\hline Missing data & 0 & $\mathrm{I}(\mathrm{I} .5 \%)$ & $2(3 \%)$ & 0 \\
\hline Mean age (standard deviation), years & $65.8(9.3)$ & $63.3(11.2)$ & $65.4(10.2)$ & $67.8(7.1)$ \\
\hline \multicolumn{5}{|l|}{ Marital status } \\
\hline Unmarried & $2(5 \%)$ & $9(13 \%)$ & $6(9 \%)$ & I (3.6\%) \\
\hline Married & $33(82.5 \%)$ & $47(68 \%)$ & $48(71.6 \%)$ & $21(75 \%)$ \\
\hline Widowed/divorced & $5(12.5 \%)$ & $12(17.5 \%)$ & $11(16.4 \%)$ & $6(21.4 \%)$ \\
\hline Missing data & 0 & $\mathrm{I}(\mathrm{I} .5 \%)$ & $2(3 \%)$ & 0 \\
\hline \multicolumn{5}{|l|}{ Share household with partner? } \\
\hline Yes & $28(70 \%)$ & 45 (65.2\%) & $52(77.6 \%)$ & $19(67.9 \%)$ \\
\hline No & $10(25 \%)$ & $17(24.6 \%)$ & $12(18 \%)$ & $6(21.4 \%)$ \\
\hline Missing data & $2(5 \%)$ & 7 (10.2\%) & $3(4.4 \%)$ & $3(10.7 \%)$ \\
\hline Mean total number of people in household (standard deviation) & $2.0(0.8)$ & $2.1(1.2)$ & $2.0(0.8)$ & $1.9(0.7)$ \\
\hline \multicolumn{5}{|l|}{ Education } \\
\hline Educational level 0 & 0 & 0 & 0 & I (3.6\%) \\
\hline Educational level I & $13(32.5 \%)$ & $16(23.2 \%)$ & $21(31.3 \%)$ & $10(35.7 \%)$ \\
\hline Educational level 2 & $10(25 \%)$ & $21(30.4 \%)$ & $17(25.3 \%)$ & $7(25 \%)$ \\
\hline Educational level 3 & $6(15 \%)$ & $10(14.5 \%)$ & II (16.4\%) & $3(10.7 \%)$ \\
\hline Educational level 4 & II (27.5\%) & $20(29 \%)$ & $15(22.4 \%)$ & $6(21.4 \%)$ \\
\hline Missing data & 0 & $2(2.9 \%)$ & $3(4.5 \%)$ & $\mathrm{I}(3.5 \%)$ \\
\hline \multicolumn{5}{|l|}{ Employment } \\
\hline Employed & $13(32.5 \%)$ & $26(37.7 \%)$ & 24 (35.8\%) & $8(28.6 \%)$ \\
\hline Not employed & $26(65.5 \%)$ & 40 (58\%) & $42(62.3 \%)$ & $17(60.7 \%)$ \\
\hline Missing data & I (2.5\%) & $3(4.3 \%)$ & I (I.5\%) & $3(10.7 \%)$ \\
\hline
\end{tabular}

Notes: Demographic characteristics of the participants were split up into 4 different subgroups. Stage I: Hearing problems recognized but no appointment with ear, nose, and throat specialist yet. Stage 2: Appointment with ear, nose, and throat specialist but no hearing aids tried out yet. Stage 3: Appointment with hearing aid acoustician and hearing aids already tried out but not owned yet. Stage 4: Hearing aid owners. Educational level 0 stands for having not graduated from school, educational levels I to 4 comprise different specifications of secondary schools, with level I signifying vocational training and level 4 general access to university studies.

group differences in educational level (Kruskal-Wallis test, $P>0.05)$. Likewise, no significant group differences were observed for employment characteristics, as (predictably with respect to the participants' age distribution) most of the individuals within all 4 subgroups were retired (chi-square test, $P>0.05)$.

\section{Statistical analyses and psychometric properties}

For the outcome presented here, the TPB model variables were generated from the direct measure items in the questionnaire (see Figure S1) by computing mean score values across the corresponding items. To examine the psychometric properties of the survey, a principal component factor analysis was applied. The suitability of the data for the analysis was investigated using the Kaiser-Meyer-Olkin test, which should give values of 0.8 or higher. The test revealed a value of 0.84 . Varimax rotation was employed with factor analysis. Factor analysis yielded four factors that accounted for $68 \%$ of the variance in the data. Loadings of the single items all together confirmed the four-factor structure (eigenvalues .1): intention (29\%), subjective norm (16\%), attitude (15\%), and behavioral control (8\%). The internal consistency of the corresponding subscales was examined using Cronbach's $\alpha$-coefficient. Cronbach's $\alpha$-coefficients were very high for intention (0.91), as well as for subjective norm (0.90), but were lower for attitude (0.48) and behavioral control (0.46). Typically, $\alpha$ should be between 0.7 and $0.9 .{ }^{27}$ However, when questionnaires address psychological constructs, lower values can be expected because of the diversity of the constructs being measured. ${ }^{28,29}$ In our case, low $\alpha$-values were mainly a result of the fact that two questions (attitude ["using HAs is useless or beneficial"] and behavioral control ["using HAs is up to me"]) showed low variability. However, omitting these items did not improve $\alpha$-values, as they also depend on the number of items, and at least three items per factor should be used. ${ }^{27}$ Thus, as these questions revealed high face validity and assumption testing approved the appropriateness of the subscale values for modeling, we decided to stay with the initial set of items. 
With the TPB models, stepwise multiple linear regressions were applied with "intention" as the dependent variable and "attitude", "subjective norm", and "behavioral control" as the independent variables. Before the calculation of the regression models, assumption testing was conducted to check for normality, linearity, homoscedasticity, and multicollinearity (variance inflation factor). No serious violations were noted. All statistical analyses were conducted using SPSS version 21 (IBM Corporation, Armonk, NY, USA). Furthermore, post hoc power analyses for the models were performed using G*Power 3.1 (http://www.gpower.hhu.de/).

\section{Results}

Table 2 shows the mean values and standard deviations for the three subscales, and the variable intention across the four subgroups of participants. They reflect the five scale values, as shown in Figure S1. There were significant group differences for subjective norm (one-way ANOVA, $P<0.001$ ), behavioral control $(P=0.014)$, and intention $(P<0.001)$. Post hoc tests (Bonferroni) revealed significant differences for intention between the subgroups (except between stage 1 and stage 2), but also revealed that the significant group effects for "subjective norm" and "behavioral control" only held for the group of HA users (stage 4) that differed from all other subgroups.

Figure 2 shows the path models with respect to the different study groups, as defined by the stage of hearing help-seeking. For participants who had recognized their hearing problems but had not yet consulted an ENT specialist (stage 1$)$, a significant $(P<0.01)$ regression coefficient could be observed for the "subjective norm" construct. In contrast to the "attitude toward the behavior", "behavioral control" also significantly contributed $(P<0.01)$ to the intention. In total, about $58 \%$ of the variance in the data of the model could be explained. For the participants who had already consulted an ENT specialist but had not yet tried out HAs (stage 2), significant $(P<0.01)$ regression coefficients could be observed for both the "subjective norm" construct and the "attitude"

Table 2 Mean and standard deviation (in parenthesis) for "attitude", "subjective norm","behavioral control", and "intention" across the four stages of hearing help-seeking

\begin{tabular}{lllll}
\hline & Attitude & $\begin{array}{l}\text { Subjective } \\
\text { norm }\end{array}$ & $\begin{array}{l}\text { Behavioral } \\
\text { control }\end{array}$ & Intention \\
\hline Stage I $(\mathrm{n}=40)$ & $3.43(0.59)$ & $2.1 I(1.12)$ & $3.15(0.70)$ & $2.63(0.93)$ \\
Stage 2 $(\mathrm{n}=69)$ & $3.21(0.60)$ & $2.17(1.15)$ & $3.36(0.89)$ & $2.81(0.93)$ \\
Stage 3 $(\mathrm{n}=67)$ & $3.35(0.66)$ & $2.48(1.04)$ & $3.25(0.97)$ & $3.28(1.00)$ \\
Stage 4 $(\mathrm{n}=28)$ & $3.44(0.64)$ & $3.64(1.02)$ & $3.82(0.87)$ & $4.48(0.65)$ \\
\hline \multicolumn{5}{l}{ Note: Scores were derived from a 5-point Likert scale (coded I to 5). }
\end{tabular}

construct. A smaller, albeit significant $(P<0.05)$, contribution came from the "behavioral control" construct. In this model, about $53 \%$ of the variance in the data could be explained. For the participants who had already tried out HAs at a visit to an acoustician but had not yet purchased them (stage 3), significant regression coefficients could again be observed for all of the three constructs. In total, about $46 \%$ of the variance in the data of the model could be explained. For the group of HA owners (stage 4), the "attitude toward the behavior" construct and the "behavioral control" construct exhibited significant $(P<0.01)$ regression coefficients with respect to intention. The "subjective norm" construct only had a minor, albeit significant $(P<0.05)$, influence on intention. About $73 \%$ of the variance in the data could be explained using this model. All models revealed a significant correlation between "attitude" and "behavioral control". However, the variance inflation factor was always far below the critical value of $10,{ }^{21}$ indicating that multicollinearity did not adversely affect the outcome of the regression analyses. Statistical power of all models was 0.95 or larger.

\section{Discussion}

As the prevalence of hearing impairment is reported to be increasing and HA uptake and use remain low, it is important to identify the key factors of help-seeking behavior and intention to use HAs. The present study pursued an approach based on an established decision-making model that applies general concepts of human behavior; namely, the TPB. To our knowledge, the TPB has not previously been applied to determine the intention to use HAs in hearing-impaired people not yet using amplification. Intention is a key factor in HA uptake, ${ }^{22}$ although there is no simple one-to-one relationship between intention and actual behavior. Several studies have demonstrated that individuals might actually decline HA provision, although they previously stated high usage motivation. ${ }^{13,14}$

The main findings of the present study are that the TPB model accounts for a substantial proportion of the intention to use HAs and that the relative contribution of the three different TPB constructs depends on the participant's stage of hearing help-seeking. The stages were chosen with respect to the typical procedure in Germany, which is based on a collaboration of general practitioners, ENT specialists, and acousticians, as opposed to the public system (eg, in the United Kingdom or Scandinavia), which incorporates audiology centers.

When comparing the TPB models across the different stages, three main observations could be made: first, the 

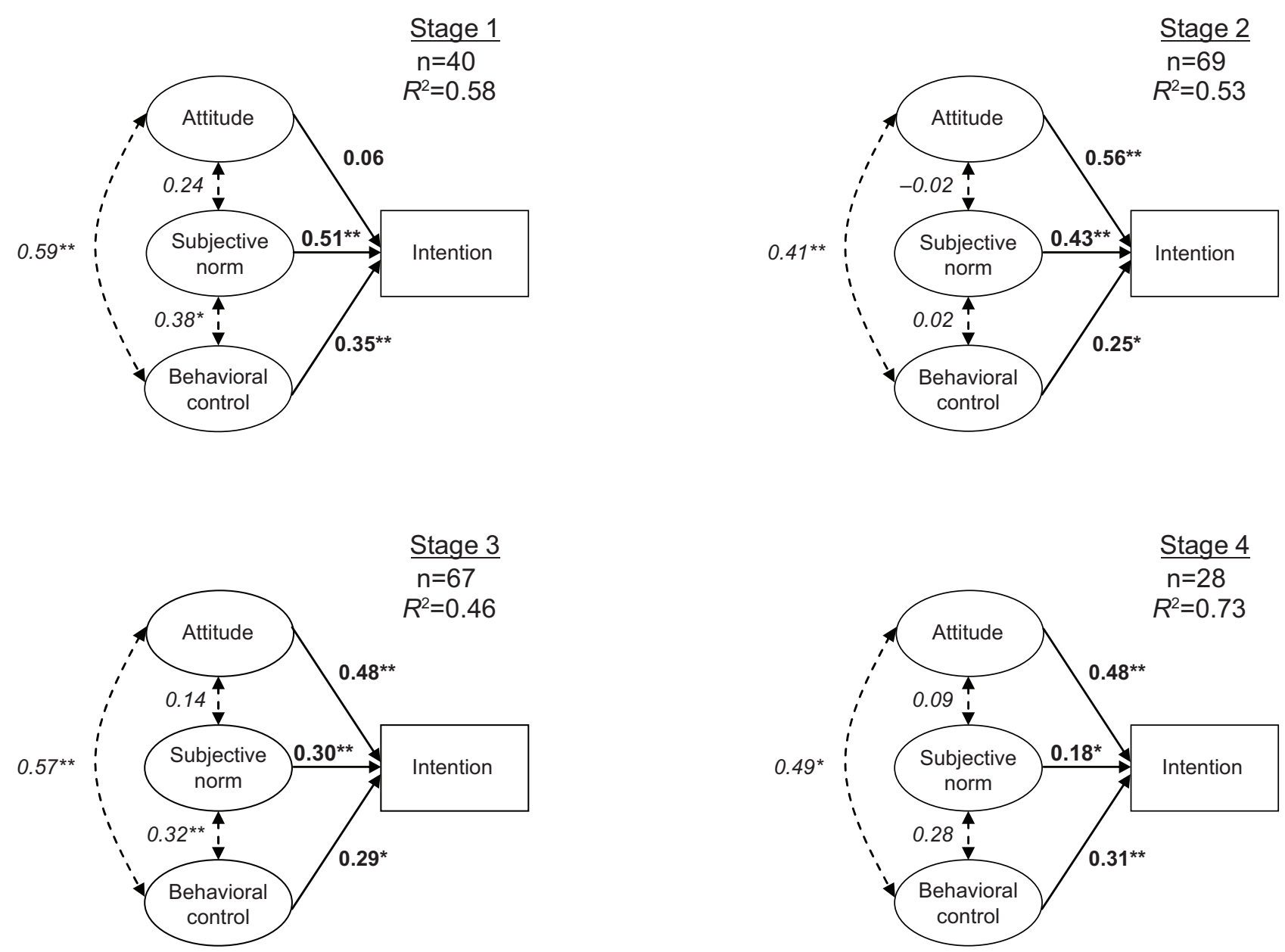

Figure 2 Path models for the group data associated with different stages of the rehabilitation process.

Notes: Stage I: Hearing problems recognized but no appointment with an ear, nose, and throat specialist yet. Stage 2: Appointment with ear, nose, and throat specialist but no hearing aids tried out yet. Stage 3: Appointment with hearing aid acoustician and hearing aids already tried out but not owned yet. Stage 4: Hearing aid owners. Bold numbers and solid lines: regression coefficients; italic numbers and dashed lines: correlation coefficients; $R^{2}$ : Goodness of fit of the model. $* P<0.05$; $* * P<0.01$.

influence of the "subjective norm" construct on intention decreased while the stages progressed; second, the influence of "attitude toward behavior" on intention was highly significant for all stages except stage 1; and third, "behavioral control" demonstrated a moderate influence on intention at all stages. This indicates a transition from a more externally driven motivation to an intrinsic motivation as help-seeking progresses.

The participants' intention to use HAs at stage 1 was mainly driven by the "subjective norm" construct. That is, intention was high if the participants could conclude that significant others in their lives, such as spouses, children, and colleagues, wanted or expected them to use HAs. This is in line with several other investigations. Mahoney et $\mathrm{al}^{30}$ found that family members or the family doctor were potential motivators with respect to HA uptake. Laplante-Lévesque et $\mathrm{al}^{14}$ stated that a hearing disability's effect on significant others is central to intervention decisions. In contrast, significant others might impede HA use when they have a negative attitude toward HAs. ${ }^{17}$

Hindhede ${ }^{31}$ discussed HA use in the conceptual framework of "normality" and pathology. Given that there is a large variability in individuals' hearing acuity, pathology is not simply based on medical terms but also largely involves a social component that defines "normality" in an individual communication context. The concept of "normality" can diametrically differ between the person at hand and his or her partner. Hindhede described, by way of example, interviews about HA use with individuals who were dominated either by significant others in their lives or by the self-experienced need to better communicate in a specific situation. She concluded that social pressure (as reflected by the "subjective norm" construct in our study) might always conflict, as the "normal" self-image of the person with hearing loss might be completely different from the concept of normality for the significant others. Thus, self-motivation based on a positive 
attitude toward HAs might be more promising with respect to HA uptake and use.

A significant influence of the construct "attitude toward the behavior" on intention could be found for stage 2 and remained apparent until stage 4 . Stage 2 included those participants who had already consulted the ENT specialist but had not yet contacted the HA dispenser/acoustician. For the intention stated by the stage 2 participants, "subjective norm" was still a significant predictor but had less of an influence than at stage 1 . This finding might highlight the distinctive role of the ENT specialist for the trajectory of aural rehabilitation. Assuming that many individuals visit the ENT specialist because of pressure from the significant others in their lives, as is evident in the stage 1 model, confirmation of the hearing disorder in terms of a medical diagnosis and the indication for HA provision might account for the significant relationship between the "attitude toward the behavior" construct and the intention scores. In this context, Laplante-Lévesque et $\mathrm{al}^{14}$ found that consultation with a medical practitioner could predispose an individual toward specific intervention decisions, depending on whether HA use or alternative options were emphasized. Thus, knowledge about the options of aural rehabilitation could also play a role regarding the intention to use HAs. Meis and Gabriel ${ }^{4}$ showed that nearly $50 \%$ of the participants in their study who were interviewed before consulting an ENT specialist were not able to provide details about basic aspects of HA fitting. In this regard, counseling can provide a cost-effective measure to consolidate the attitude toward HAs. ${ }^{32}$

Individuals at a more advanced stage of hearing helpseeking are more informed about HAs as they gain practical experience with hearing instruments. In Germany, it is mandatory to try out different HA systems before purchasing one. This period is covered by stage 3 ; the corresponding TPB model again revealed a highly significant contribution of the "attitude toward the behavior" construct, but a decreasing influence of the "subjective norm" on intention. These results stabilized at stage 4, which included HA owners. Here, "subjective norm" had only a marginal, albeit statistically significant, influence. This resembles the results of Wiesner and Tesch-Römer's ${ }^{22}$ study. These researchers applied the TPB to analyze predictors of HA use in elderly people, who had all been provided with HAs for the first time, and found that the intention-to-use HA amplification was mainly influenced by the participants' attitude toward HAs. In contrast to the present results, their model did not show "subjective norm" or "behavioral control" to be a statistically significant contributor.
The "behavioral control" construct was a significant factor in all the models described in the present study, although it always only yielded a moderate regression coefficient of around 0.3 . That is, at all stages, the participants' intention to use HAs was, to a certain degree, influenced by the question of whether the factors that might hinder or facilitate HA use were under individual control. People who perceived fewer barriers revealed a greater intention to use HAs. The wording of the items that addressed "behavioral control" was rather general (see Figure S1). However, it might be speculated that the factors behind this include cosmetic appearance or handling issues, ${ }^{33,34}$ as well as unwanted noise or changed sound quality. ${ }^{10}$ This also ties in with findings of Saunders et al. ${ }^{28}$ Based on the "health belief model", they developed a "health belief questionnaire" that considered perceived barriers (eg, "HAs are uncomfortable", "HAs are ugly") as a subscale. It was demonstrated that perceived barriers were a significant factor associated with help-seeking behavior of the hearing-impaired people examined.

The stages of hearing help-seeking applied in the present study are in line with another theoretical approach; namely, the Transtheoretical Stages-of-Change Model. ${ }^{14,18,19,35}$ This model defines different stages of change that the person undergoes, such as precontemplation (no thoughts or plans to change behavior), contemplation (awareness of the problem), preparation (intention to take action), maintenance (maintaining changed behavior over a longer period of time), and relapse (returning to the old behavior or abandoning new changes). Concretely, our four stages relate to contemplation (stage 1), preparation (stages 2 and 3), and maintenance (stage 4). With respect to the aim of increasing HA uptake and HA use among hearing-impaired people, the different models presented here suggest that measures such as public relation activities and counseling strategies should be addressed, taking into account the different effects on the several stages of hearing help-seeking.

Further interesting findings emerged from the mean scale values as given in Table 2: whereas the values of "attitude" were stable across the four subgroups, significant group differences were found for "subjective norm" and "behavioral control". These effects were caused by the group of HA users (stage 4) who showed high mean values for both constructs. Thus, even after HAs had been obtained, individuals reported social pressure to use them, although the influence of "subjective norm" on intention was weak in this subgroup. A significant group difference was also found for intention. Predictably, intention increased as the participants proceeded on the trajectory of aural rehabilitation. 
Certain limitations might be observed with the study, as the TPB models explained only about $50 \%$ of the variance in the data. Thus, the constructs considered predict the intention to use HAs only to some extent. A review of TPB models revealed an explanation for values of around $40 \%$ variance, ${ }^{36}$ and some methodological restrictions of the TPB might limit the proportion of variance accounted for. ${ }^{37}$ Psychometric analysis of the questionnaire revealed very good internal consistency for the measures of "subjective norm" and intention, whereas it was clearly lower for "attitude" and "behavioral control". Thus, when regarding the interpretation of the data, it should be kept in mind that "attitude" and "behavioral control" might represent less homogeneous constructs than "subjective norm" and intention. Further, although our participants represented a wide range of demographic characteristics, it cannot be assumed that the group in this study is representative of the general population. Nevertheless, we do not see a strong bias with respect to the main finding of how the outcome of the models depends on the stage of hearing help-seeking, at least if the cognitive state and other resources of the people are comparable to the participants who were actively involved in the present study. Moreover, the validity of the TPB model is indirectly supported by Solheim, ${ }^{34}$ who, as a result of factor analysis of his survey's outcome, found that positive expectations, social pressure, and perceived barriers were related to HA use. These are factors that correspond well with the constructs of "attitude", "subjective norm", and "behavioral control".

\section{Conclusion}

This study indicates a transition from an "external-based" motivation to use HAs at the initial stage of hearing helpseeking to more "self-motivated" HA use as the process of HA provision proceeds. The main changes appear at the stage of the visit to an ENT specialist. After that, the intention to use HAs is significantly related to the attitude toward HAs, whereas the effect of significant others decreases. Behavioral control has a significant, albeit moderate, effect on intention at all stages.

The results speak well for counseling strategies that explicitly consider the individual trajectory of hearing help-seeking: at the initial stage significant others should be integrated in the counseling process, as they might support active help-seeking behavior, and concise information about the possible benefits of HAs should be given to support a positive attitude toward HAs. Throughout the whole process of HA provision, potential barriers should be addressed to promote a feeling of control with regards to HA usage.

\section{Acknowledgments}

This study was funded by the German Federal Ministry of Education and Research (reference 01EZ0741). The authors are grateful to Professor Icek Ajzen for reviewing the draft of the TPB parts of the questionnaire. Thanks to Dr Dirk Beutner and Dr Alexander Volk (Cologne) for help in subject acquisition. Thanks to Müge Kaya (Oldenburg) for conscientiously preparing the digital datasheets and to Eleanore Lazell for proofreading the manuscript.

\section{Disclosure}

The authors report no conflicts of interest in this work.

\section{References}

1. Zhan W, Cruickshanks KJ, Klein BE, et al. Generational differences in the prevalence of hearing impairment in older adults. Am J Epidemiol. 2010;171(2):260-266.

2. van den Brink RH, Wit HP, Kempen GI, van Heuvelen MJ. Attitude and help-seeking for hearing impairment. Br J Audiol. 1996;30(5): 313-324.

3. Popelka MM, Cruickshanks KJ, Wiley TL, Tweed TS, Klein BE, Klein R. Low prevalence of hearing aid use among older adults with hearing loss: the Epidemiology of Hearing Loss Study. J Am Geriatr Soc. 1998;46(9):1075-1078.

4. Meis M, Gabriel B. Barriers in hearing instrument provision - From a consumer perspective. Proceedings of the 51th International Congress of Hearing Aid Acousticians; 2006. Frankfurt am Main, Germany. Available from: http://www.euha.org/congress/conference-proceedings-on-cd-rom/. Accessed July 24, 2104.

5. Davis A. Population study of the ability to benefit from amplification and the provision of a hearing aid in 55-74-year-old first-time hearing aid users. Int J Audiol. 2003;42 Suppl 2:2S39-2S52.

6. Duijvestijn JA, Anteunis LJC, Hoek CJ, Van Den Brink RH, Chenault MN, Manni JJ. Help-seeking behaviour of hearing-impaired persons aged $>$ or $=55$ years; effect of complaints, significant others and hearing aid image. Acta Otolaryngol. 2003;123(7):846-850.

7. Smeeth L, Fletcher AE, Ng ES, et al. Reduced hearing, ownership, and use of hearing aids in elderly people in the UK - the MRC Trial of the Assessment and Management of Older People in the Community: a cross-sectional survey. Lancet. 2002;359(9316):1466-1470.

8. Bertoli S, Staehelin K, Zemp E, Schindler C, Bodmer D, Probst R. Survey on hearing aid use and satisfaction in Switzerland and their determinants. Int J Audiol. 2009;48(4):183-195.

9. McCormack A, Fortnum H. Why do people fitted with hearing aids not wear them? Int J Audiol. 2013;52(5):360-368.

10. Knudsen LV, Öberg M, Nielsen C, Naylor G, Kramer SE. Factors influencing help seeking, hearing aid uptake, hearing aid use and satisfaction with hearing aids: a review of the literature. Trends Amplif. 2010;14(3):127-154.

11. Meyer C, Hickson L. What factors influence help-seeking for hearing impairment and hearing aid adoption in older adults? Int J Audiol. 2012;51(2):66-74.

12. Cox RM, Alexander GC, Gray GA. Who wants a hearing aid? Personality profiles of hearing aid seekers. Ear Hear. 2005;26(1):12-26.

13. Meister H, Walger M, Brehmer D, von Wedel UC, von Wedel H. The relationship between pre-fitting expectations and willingness to use hearing aids. Int J Audiol. 2008;47(4):153-159.

14. Laplante-Lévesque A, Hickson L, Worrall L. Predictors of rehabilitation intervention decisions in adults with acquired hearing impairment. J Speech Lang Hear Res. 2011;54(5):1385-1399.

15. Lockey K, Jennings MB, Shaw L. Exploring hearing aid use in older women through narratives. Int J Audiol. 2010;49(8):542-549. 
16. Southall K, Gagné JP, Jennings MB. Stigma: a negative and a positive influence on help-seeking for adults with acquired hearing loss. Int J Audiol. 2010;49(11):804-814.

17. Kochkin S. MarkeTrak VII: Obstacles to adult non-user adoption of hearing aids. Hearing J. 2007;60(4):27-43.

18. Rosenstock I. Historical orignis of the health belief model. Health Educ Behav. 1974;2(4):328-335.

19. Prochaska JO, DiClemente CC. Trans-theoretical therapy - toward a more integrative model of change. Psychotherapy. 1982;19(3):276-288.

20. Saunders GH, Chisolm TH, Wallhagen MI. Older adults and hearing help-seeking behaviors. Am J Audiol. 2012;21(2):331-337.

21. Ajzen I. The Theory of Planned Behaviour. Organ Behav Hum Decis Process. 1991;50(2):179-211.

22. Wiesner M, Tesch-Römer C. Hörgerätebenutzung im Alter: Der Zusammenhang zwischen Intention und Verhalten. [Usage of hearing aids in the elderly: the relationship between intention und behaviour]. Z Gerontol Geriatr. 1996;29(4):273-279. German.

23. Hickson L, Meyer C, Lovelock K, Lampert M, Khan A. Factors associated with success with hearing aids in older adults. Int J Audiol. 2014;53(suppl 1):S18-S27.

24. Ajzen I. From intention to actions: a theory of planned behavior. In: Kuhl J, Beckmann J, editors. Action Control: From Cognition to Behavior. Heidelberg: Springer; 1985:11-39.

25. Francis JJ, Eccles MP, Johnston M, et al. Constructing Questionnaires Based on the Theory of Planned Behaviour. A Manual for Health Service Researchers. Newcastle: University press; 2004.

26. Gates GA, Murphy M, Rees TS, Fraher A. Screening for handicapping hearing loss in the elderly. J Fam Pract. 2003;52(1):56-62.
27. Streiner DL, Norman GR. Health Measurement Scales: A Practical Guide to Their Development and Use. 3rd ed. Oxford, UK: Oxford University Press; 1995.

28. Saunders GH, Frederick MT, Silverman S, Papesh M. Application of the health belief model: development of the hearing beliefs questionnaire (HBQ) and its associations with hearing health behaviors. Int J Audiol. 2013;52(8):558-567.

29. Kline P. The Handbook of Psychological Testing. 2nd ed. London: Routledge; 1999.

30. Mahoney CF, Stephens SD, Cadge BA. Who prompts patients to consult about hearing loss? Br J Audiol. 1996;30(3):153-158.

31. Hindhede AL. Negotiating hearing disability and hearing disabled identities. Health (London). 2012;16(2):169-185. London.

32. Vuorialho A, Karinen P, Sorri M. Counselling of hearing aid users is highly cost-effective. Eur Arch Otorhinolaryngol. 2006;263(11):988-995.

33. Schum DJ. Perceived hearing aid benefit in relation to perceived needs. J Am Acad Audiol. 1999;10(1):40-45.

34. Solheim J. Preconceptions and expectations of older adults about getting hearing aids. J Multidiscip Healthc. 2011;4:1-8.

35. Laplante-Lévesque A, Hickson L, Worrall L. Stages of change in adults with acquired hearing impairment seeking help for the first time: application of the transtheoretical model in audiologic rehabilitation. Ear Hear. 2013;34(4):447-457.

36. Armitage CJ, Conner M. Efficacy of the Theory of Planned Behaviour: a meta-analytic review. Br J Soc Psychol. 2001;40(Pt 4):471-499.

37. Greve W. Traps and gaps in action explanation: theoretical problems of a psychology of human action. Psychol Rev. 2001;108(2):435-451. 


\section{Supplementary material}

\begin{tabular}{|c|c|c|c|c|c|}
\hline \multicolumn{6}{|c|}{ Intention (4 items) } \\
\hline \multicolumn{6}{|c|}{ I have decided to use hearing aids } \\
\hline$\circ$ & $\circ$ & $\circ$ & ○ & \multicolumn{2}{|l|}{ o } \\
\hline strongly agree & agree & undecided & disagree & \multicolumn{2}{|l|}{ strongly disagree } \\
\hline \multicolumn{6}{|c|}{ It is important for me to use hearing aids } \\
\hline o & $\circ$ & o & ○ & \multicolumn{2}{|l|}{$\circ$} \\
\hline strongly agree & agree & undecided & disagree & \multicolumn{2}{|l|}{ strongly disagree } \\
\hline \multicolumn{6}{|c|}{ I plan to use hearing aids } \\
\hline ० & o & o & o & \multicolumn{2}{|l|}{$\circ$} \\
\hline strongly agree & agree & undecided & disagree & \multicolumn{2}{|l|}{ strongly disagree } \\
\hline \multicolumn{6}{|c|}{ I believe I will use hearing aids } \\
\hline$\circ$ & $\circ$ & ○ & ○ & \multicolumn{2}{|l|}{$\circ$} \\
\hline strongly agree & agree & undecided & disagree & \multirow{2}{*}{\multicolumn{2}{|c|}{ strongly disagree }} \\
\hline \multicolumn{4}{|c|}{ Attitude (4 items) } & & \\
\hline \multicolumn{6}{|c|}{ Using hearing aids is... } \\
\hline & I & 2 & 3 & 4 & 5 \\
\hline worthless & $\circ$ & $\circ$ & ○ & $\circ$ & o worthwhile \\
\hline uncomfortable & o & ○ & ○ & $\circ$ & o comfortable \\
\hline useless & o & o & ○ & $\circ$ & o beneficial \\
\hline repellent & $\circ$ & o & ○ & $\circ$ & o appealing \\
\hline \multicolumn{6}{|c|}{ Subjective norm ( 3 items) } \\
\hline \multicolumn{6}{|c|}{ People who are important to me push me to use hearing aids } \\
\hline$\circ$ & $\circ$ & ○ & ○ & $\circ$ & \\
\hline strongly agree & agree & undecided & disagree & \multicolumn{2}{|l|}{ strongly disagree } \\
\hline \multicolumn{6}{|c|}{ People who are important to me ask me to use hearing aids } \\
\hline$\circ$ & $\circ$ & $\circ$ & ○ & $\circ$ & \\
\hline strongly agree & agree & undecided & disagree & \multicolumn{2}{|l|}{ strongly disagree } \\
\hline \multicolumn{6}{|c|}{ People who are important to me expect me to use hearing aids } \\
\hline$\circ$ & $\circ$ & $\circ$ & $\circ$ & $\circ$ & \\
\hline strongly agree & agree & undecided & disagree & strongly disagree & \\
\hline Behavioral co & & & & & \\
\hline For me, using $\mathrm{h}$ & uld be $\mathrm{d}$ & & & & \\
\hline & 1 & 2 & 3 & 4 & 5 \\
\hline & $\circ$ & $\circ$ & ○ & $\circ$ & o easy \\
\hline I am sure that I & o use he & & & & \\
\hline$\circ$ & $\circ$ & $\circ$ & $\circ$ & $\circ$ & \\
\hline strongly agree & agree & undecided & disagree & strongly disagree & \\
\hline Using hearing ai & & & & & \\
\hline$\circ$ & $\circ$ & $\circ$ & $\circ$ & $\circ$ & \\
\hline strongly agree & agree & undecided & disagree & strongly disagree & \\
\hline Additional qu & regard & (3 items) & & & \\
\hline Do you feel tha & aring pro & & & & \\
\hline$\circ$ & $\circ$ & & & & \\
\hline yes & no & & & & \\
\hline If yes, how seve & aring pro & & & & \\
\hline In quiet listenin & & & & & \\
\hline$\circ$ & $\circ$ & $\circ$ & $\circ$ & $\circ$ & \\
\hline very mild & mild & moderate & severe & very severe & \\
\hline In adverse lister & & & & & \\
\hline$\circ$ & $\circ$ & $\circ$ & $\circ$ & $\circ$ & \\
\hline very mild & mild & moderate & severe & very severe & \\
\hline
\end{tabular}

Figure SI Theory of planned behavior questionnaire.

Patient Preference and Adherence

\section{Publish your work in this journal}

Patient Preference and Adherence is an international, peer-reviewed, open access journal that focuses on the growing importance of patient preference and adherence throughout the therapeutic continuum. Patient satisfaction, acceptability, quality of life, compliance, persistence and their role in developing new therapeutic modalities and compounds to optimize clinical outcomes for existing disease states are major areas of interest for the journal. This journal has been accepted for indexing on PubMed Central. The manuscript management system is completely online and includes a very quick and fair peer-review system, which is all easy to use. Visit http://www. dovepress.com/testimonials.php to read real quotes from published authors.

\footnotetext{
Submit your manuscript here: http://www.dovepress.com/patient-preference-and-adherence-journal
} 